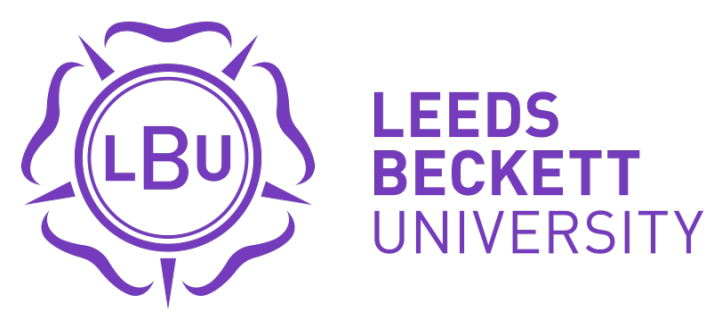

Citation:

Fletcher, TE and Meir, D (2017) The transformative potential of using participatory community sport initiatives to promote social cohesion in divided community contexts. International Review for the Sociology of Sport, 54 (2). pp. 218-238. ISSN 1012-6902 DOI: https://doi.org/10.1177/1012690217715297

Link to Leeds Beckett Repository record:

https://eprints.leedsbeckett.ac.uk/id/eprint/3972/

Document Version:

Article (Accepted Version)

The aim of the Leeds Beckett Repository is to provide open access to our research, as required by funder policies and permitted by publishers and copyright law.

The Leeds Beckett repository holds a wide range of publications, each of which has been checked for copyright and the relevant embargo period has been applied by the Research Services team.

We operate on a standard take-down policy. If you are the author or publisher of an output and you would like it removed from the repository, please contact us and we will investigate on a case-by-case basis.

Each thesis in the repository has been cleared where necessary by the author for third party copyright. If you would like a thesis to be removed from the repository or believe there is an issue with copyright, please contact us on openaccess@leedsbeckett.ac.uk and we will investigate on a case-by-case basis. 


\title{
The transformative potential of using participatory community sport initiatives to promote social cohesion in divided community contexts
}

David Meir, School of Health, Science and Technology, University Centre, Blackburn College, UK, david.meir@blackburn.ac.uk

Thomas Fletcher, Institute for Sport, Physical Activity and Leisure, School of Events, Tourism and Hospitality Management, Leeds Beckett University, UK, t.e.fletcher@leedsbeckett.ac.uk

\begin{abstract}
Sports are popularly believed to have positive integrative functions and are thought therefore, to be able to galvanise different, and sometimes divided, communities through a shared sporting interest. UK Government and policy rhetoric over the last two decades has consistently emphasised the positive role sport can play in building more cohesive, empowered and active communities. These positive impacts are particularly important for communities with high numbers of young people from disadvantaged backgrounds. The purpose of this paper is to reflect on the challenges associated with co-producing a participatory community sport initiative with 28 young people in working towards greater social cohesion in an ethnically segregated borough in North West England. Although a great deal was learnt from working towards this, the initiative was ultimately unsuccessful as young people, for a variety of reasons, removed themselves from the process. A major contribution of this paper is how we reflect on the realities of project failure and how future community sport initiatives might have greater success. In particular, we argue that for sport to make a difference, participants must be enabled to develop a sense of civic engagement and critical awareness which go beyond either sport or community development, emphasising instead, wider socio-political development.
\end{abstract}

Keywords: Asian, Divided communities, Participatory methods, Social cohesion, Sport

\section{Introduction}

Sports are consistently thought to have positive integrative functions that enable them to play a role in contributing to the resolution of complex social issues inherent to and existing within, different communities. More and more across both the developing world and within the UK, sport is being used as a tool to bring divided communities together through the promotion of specific values that can foster understanding, tolerance and peace (Lindsey, 2013; Lindsey and O'Gorman, 2015; Schulenkorf, 2012). The belief is that sport can contribute towards wider social objectives and can 'build bridges between people, help overcome cultural differences and spread an atmosphere of tolerance' (Beutler, 2008: 359). Clearly there are limits to this potential, some of which we discuss below.

This paper is concerned with the potential of sport to act as a tool for facilitating social cohesion. Social cohesion is generally defined as solidarity and togetherness and is often used interchangeably with community cohesion. Cantle (2009) identifies cohesive communities as having a common vision, a sense of belonging, positive appreciation of diversity and strong relationships being built and maintained between people from different backgrounds and different neighbourhoods. The local council for the borough focused upon here adopts a holistic view of community cohesion in its suggestion that a cohesive society is one which promotes civic engagement, a sense of belonging, interaction between communities, and a safe and fair society that promotes equality of opportunity 
(Blackburn and Darwen Strategy, 2013). Forrest and Kearns (2001) identify a series of 'domains' that characterise social and community cohesion. These domains are common values and a civic culture, social order and social control, social solidarity and reductions in wealth disparities, social networks and social capital, place attachment and identity. As will be demonstrated shortly, these domains resonate clearly with the issues faced by participants within this research. Through an understanding of these domains this paper is concerned with asking whether a participatory community sport initiative has the potential to develop social cohesion within an ethnically segregated East Lancashire borough $^{1}$ in the North West of England. The borough in question has some of the highest levels of cultural, geographical and educational segregation in the country and is, therefore, an interesting case study.

The potential of promoting social cohesion through sport within a divided borough is conceptualised here within a social transformation framework that acknowledges the possibility for sport to provide small scale social change through forms of cultural transformation. In order to develop an initiative with the intention of delivering transformational aims and objectives it is crucial to take into account the possibility for methodological innovation and action. Participatory Action Research (PAR) is in principle a group activity where people (notwithstanding their differences, prejudices, conflicts) come together to work collectively and collaboratively on an issue of mutual concern. It is considered to be a democratic, equitable, liberating and life enhancing form of qualitative research and enables knowledge to be jointly produced through critical interpretations and readings of the world, which are accessible, understandable and actionable for all those involved (Schinke et al., 2013). PAR was adopted, based on these benefits, but also with a recognition that implementation is fraught with complexity (see Whitely and Johnson, 2015). We discuss our approach to PAR in more detail below, but it is worth highlighting here that our ultimate intention for adopting PAR was in order to ensure that any proposed interventions put participants at the heart of what we did and in an effort to produce 'welcoming and inclusive' interventions which could lead to transformational outcomes. However, as we discuss throughout, while clearly well intentioned, this particular initiative failed against its initial objectives.

This paper begins by providing some much needed context, including discussing migration and the North West of England and the impact of migration on existing communities. Next, we provide an overview of the potential of sport to contribute to social cohesion before introducing our methods and, in particular, our PAR approach. Following this we present our data and reflect on the project's limitations and how future initiatives might fare better.

\section{Research Context}

\section{The North (West) and migration}

This paper is underpinned by data collected in Lancashire, a county located in the North West of England, and well known for its complex race relations (see below). Across the UK, racialised tensions between White and minoritised ethnic communities have been exacerbated since the turn of the century. According to Sanderson and Thomas (2014) these have become symptomatic of a complex interplay across the country between territoriality and 'race'. They argue that how we understand race relations in northern England must be understood at the intersection of 'complex urban settlement and resettlement, and the local configuration of the regions, towns and the populations 
surrounding' (Sanderson and Thomas, 2014: 1169). Racialised tensions in northern England are not new. A series of widely publicised riots and racial disturbances have occurred in Bradford since the mid-1990s, which have often been attributed to the segregation that has been identified between the various ethnic groups present in the city (see Alexander, 2005). In 2001, further riots in other northern towns, Oldham (April) and Burnley (June), again culminating in Bradford (July), led some critics to describe northern England as Britain's main region for British and South Asian ${ }^{2}$ dissatisfaction (Alam, 2004).

During the post-Second World War and post-colonial periods, Britain needed cheap labour to facilitate national recovery. Directly related to British colonial rule on the Indian subcontinent and Caribbean, families from these regions were encouraged to move to Britain to fulfil this need (Kalra 2000). Due to its burgeoning industries (primarily mills and collieries), Lancashire was a popular settling place. The vast majority of migrants arrived in Lancashire following the partition of India and Pakistan in 1947. Many came to work within and support the manufacturing economy of the region. In the main they came from the state of Gujarat in India, more specifically from the areas of Surat and Baruch (Kelly, 1990). Their settlement was consistent with the process of 'chain migration'; facilitated by specific kinship networks. This migration gained momentum due to periodic labour shortages within the main industries and although the initial migrants were male, by the late 1960s and early 1970s wives and children joined them to settle in the towns with other migrants starting to arrive from different areas including Kashmir and later, Pakistan and Bangladesh. In spite of the existence of migrant communities, historically, illustrations of northern England depict the region as a White monolith; concealing the region's ethnic diversity (Fletcher and Swain, 2016).

Like in other regions of northern England, migrants faced an immediate post-migration phase of racial politics from both the government and the populace, which often resulted in restricted access to leisure opportunities, employment and other services that were taken for granted by the majority White population. Kelly (1990) explains how the local White population remained resentful towards migrants due to residual nationalistic fervour that remained from the war. Kelly also referred to lingering resentment about the decline of the British Empire and more local concerns about how their own Lancastrian working class traditions were in decline due to, for example, failing industry, old housing stock and an ageing population. The belief was that migrants from South Asia in particular, were introducing 'irreversible changes to the social composition of Britain...they provided competition for jobs and housing, had excessively large families and were reluctant to change' (Fletcher and Walle, 2015: 232). This animosity would only increase as the textile industry and local economy went into further decline and unemployment began to rise.

Due to their phenotypical appearance and conspicuous cultural differences, such as clothing and culinary practices, post-war migrants were 'racially' marked. Such 'racialisation' largely restricted access to cultural resources and spaces taken for granted by White people, and contributed to racial prejudice and institutionalised racism (Stephenson 2006). We are conscious not to homogenise the migrant experience as one revolving around exclusion and prejudice from and by the White majority. Of course, not all migrant and diasporic experiences and narratives are the same. Central to all migrant and diasporic groups are their internal differences (gender, class, age, political affiliations etc.). According to Brah (1996: 183), migrant and diasporic communities are a heterogeneous collective of different narratives, as the journeys undertaken by their members, and their subsequent experiences in the host society are subjective. We are not suggesting that all whom migrated to the North West of England were inevitably racialised and excluded - there will have been instances of conviviality for 
instance (see Gilroy, 2008) - but many certainly were. For the majority of those who were, a direct consequence was that, regardless of their background or level of education pre-migration, they were initially employed in low-paid manual occupations. As a result, migrant groups would tend to gravitate to certain (cheaper) areas of towns and cities, meaning that these areas quickly became enclaves, associated with these groups, and subsequently racialised. Such clustering served, not only as a defensive function against racism, but also led to the creation of essential infrastructure, specific to the community, such as places of worship, community centres, food stores and other specialist retailers. Therefore, as Dashper and Fletcher (2013: 1228) argue, cultural identities 'are contextually contingent; influenced heavily by time and place and the extent to which they are embedded in the culture of their geographical location'. The next section provides further context on the research location.

\section{An ethnically diverse and divided borough}

According to Census figures for the borough in 1981, 13\% (15,162 people) of the local population was born outside the UK. Of that number, 8,339 came from India, 5,692 came from Pakistan and 1,131 came from East Africa. The proportion of minoritised ethnic people has continued to grow over the last three decades. According to the 2011 Census the borough has a population of 147,489, of which 41,494 (28\%) identified themselves as South/British Asian. The proportion of South/British Asians residing in this borough is by far the highest in Lancashire. The long established and growing South/Asian British communities are fairly evenly divided between those of Indian (13.4\%) and Pakistani (12.2\%) heritage but almost all are Muslim (96\%) which makes it, proportionately, the second largest Muslim population in the country outside of Birmingham (97\%).

The borough also contains significant geographic separation. In order to fully understand this separation, the demographic composition of different wards ${ }^{2}$ within in, of which there are twenty three, need to be analysed in greater detail. This is not in any attempt to claim that geographical and therefore, social divisions are the result of self-imposed segregation by the South/British Asian communities; this would clearly distort the wider structural and ideological challenges they have faced in the past and continue to face today. Rather it is being analysed to explain the current situation within the borough and to highlight how this impacts on social cohesion now and might in the future. Thirteen wards within the borough have a White British population of over $90 \%$, a further two wards have a White British population of over $75 \%$. In contrast, there are four wards with a population of over $60 \%$ South/British Asian and four wards with a more mixed profile (Census 2011). This does not tell the full story, however, as those wards with a mixed profile have experienced quite a significant drop in the White British population (due to White flight) between 2001 and 2011 of between 10\% and $23 \%$, and those four wards with a higher percentage of South/British Asian residents have seen a reduction in the White British population of between 26 and $47 \%$.

The borough has one of the youngest populations in England. Thirty-one per cent of its citizens are under the age of 19 with the South/British Asian community having a particularly youthful profile, as $46 \%$ currently are under the age of 19 . This means that both the number and proportion of South/British Asians within the overall population is likely to continue to grow (Cantle, 2009). On current projections, by the next Census, ethnic separation is anticipated to rise further. 
Geographic segregation is strongly associated with other forms of social and cultural segregation, particularly education, and is also closely aligned with patterns of deprivation. From an economic perspective, the borough was ranked 13th of all local authorities in England and Wales on the 2015 Index of Multiple Deprivation. As a result, there is an understandable concern over threats to scarce resources, such as jobs and welfare. As became evident after the UK's decision to leave the European Union (EU) following the Referendum on June 23, 2016, negative perceptions of (increasing) immigration, alongside wider issues of austerity and deprivation is more marked for economically marginalised groups within society (Speed, 2016). Within the borough $13.6 \%$ of the population are in fuel poverty and wages are $18 \%$ lower than the national average (Blackburn and Darwen Strategy, 2013). In total $10.3 \%$ of the population are unemployed, with $20.7 \%$ claiming some form of working age benefit and $31.2 \%$ of the population are economically inactive (Blackburn and Darwen Strategy, 2013). Given this context, what (if any) role might sport play in facilitating greater social cohesion and, if so, with what effect?

\section{Sport and social cohesion}

UK Government and policy rhetoric over the last two decades has consistently emphasised the positive role sport can play in building more cohesive, empowered and active communities (DCMS 2008). At the community level, sport has been advocated as a mechanism to promote a socially cohesive society, encourage strong community bonds, reduce crime rates, and offer access to positive mentors (Chamberlain, 2013; Dacombe, 2013). These positive impacts are particularly important for communities with high numbers of young people from disadvantaged backgrounds. Researchers point to the potential for sport to build relationships and social cohesion across religious, ethnic and economic lines, but there is little explicit evidence to support this assertion (Beutler 2008). In more recent times, research into sport for development and Peace (SDP) has advocated how sport may be used as a tool to intervene within complex and deeply divided societies and to promote a greater level of mutual understanding and conflict resolution at grassroots level between different cultural groups within a specific community (Darnell, Whitley and Massey, 2016; Lindsey, 2013; Sugden, 2015).

Sport based interventions are growing evermore popular as a tool to engage with young people (see Lindsey, 2013; Stride and Fitzgerald, 2017), mainly because they are viewed as a way to alleviate the distorted relations that exist between young people and the agencies who engage with them (Haudenhuyse et al., 2012). They provide the opportunity for social, interactive and co-operative behaviour, contributing to cultural learning, trust and the establishment of networks (Haudenhuyse et al., 2012). If facilitated in the correct way, positive experiences will dominate and the creation of multiple inclusive social identities can be achieved (Schulenkorf 2010). While the positive impact of participation in sport on individuals and communities is widely promoted, sport can also exclude individuals and groups and further divide communities. Sport is certainly not a social panacea. Perkins et al's (2000) review of youth programs in the US for example, notes that ethnic minoritised youth, particularly those living in non-affluent communities, do not participate equally in organised sport. This means they can become alienated from broader national and community networks and support that enable access to social and economic resources. Spaaij (2013) suggests similarly, criticising any notion of sport as a harmonious multi-cultural meeting point as unrealistic. This is not to say that sport cannot play a role in minimising inequality, but it cannot solve society's ills independently. Sport must form part of a series of wider processes, which aim to tackle the root(s) of inequality. 


\section{Methodology}

\section{Background and context}

David Meir originally moved to this borough as a student-teacher in 2003 and took up a position at a local college. It takes time to understand a town - especially as an outsider - but as an outsider you are also in a position where you notice what is obvious to you yet highly normalised by those who have established roots (Fletcher, 2014). As Meir spent more time in the borough, that there were high levels of ethnic division became more and more apparent.

Utilising his role as a Lecturer in Sport at the college, Meir started to think about ways in which sport might be utilised as a tool for trying to reduce these divisions. He wanted to develop a project that would enable the young people to address these divisions for themselves; not unlike the objectives of the organisation Football 4 Peace International (F4P). Meir contacted the organisation and made a visit to a project in Jerusalem in July 2013 to undertake some primary data collection. The intention of this research was to look at the ways in with F4P implemented their approach and to see whether good practice could be transferred to a project within the borough. A key finding from this research was that for a value based sport project to have an impact on the wider community, they must be 'undertaken in collaboration with individuals and communities in which the programmes will be delivered, ensuring both a level of ownership for the participants and a level of cultural understanding for the organisation' (Meir, 2017: 27). It was from this understanding that the initial ideas emerged for the project discussed in this paper.

Naturally, the authors appreciate that what works in one context is not necessarily transferrable into others. Indeed, it would be highly misleading t0 describe the project herein as being guided by the same kind of SDP principles underpinning projects like F4P as this is not the case. This initiative always had localised social cohesion at its core and any engagement that Meir had with F4P was in order to understand, broadly, if and how sport can be applied in divided community contexts. This is an important distinction to make for, as Coalter (2010) has previously argued, SDP is often vaguely theorised, with some academics being too quick to refer to their work as SDP when, in reality, it is not. He argues that some sport programmes are guilty of, among other things, confusing potential micro-level individual outcomes with community and broader macro-level impacts and seeking to solve broad gauge problems via limited focus interventions. The project discussed in this paper is best described as 'community sport development' as, rather than being concerned with addressing development goals on a national or even international level, it is more local and community focused, with the aim of resolving a specific community issue through participant engagement (Hylton and Totten, 2013).

The fundamental belief of the initiative described here was that it should be participant-led and developed from the bottom up, ensuring participant ownership of and throughout the process. The intention of being participant-led is of course limited by participants' understanding of the approach, alongside the intention of those participants to truly 'own' the approach. However, it was also acknowledged that to have imposed an approach on participants would have led to the initiative being researcher-led, top down and didactic in structure, all of which we wanted to avoid. The project was initially designed by Meir, taking into account some of the good practice witnessed while observing the F4P initiative, before engaging local youth centre practitioners in further co- 
development. The youth centre was approached in the acknowledgement that while Meir felt he had developed an understanding of applying sport in divided community contexts, he did not necessarily have a sufficiently nuanced understanding of the local environment or its communities. Meir's experience of sport initiatives and the youth workers' experience of working with local young people provided the necessary expertise to develop a sports project that sought to address social cohesion through participatory approaches.

\section{Participatory Action Research}

Contemporary society has seen a shift in rhetoric around the engagement of young people in decision making processes; especially their roles in social science research (Christens and Dolan 2011). In part, this re-articulation has emerged from ideas associated with a social justice agenda, including the importance of fairness, equity and citizenship. This kind of thinking has led to an increasing recognition that there is a need to value and listen to the voices of young people to better understand their experiences (Stride and Fitzgerald, 2017). The result being that, 'Young people have become positioned as 'experts' in their own lives, rather than deemed incapable of making useful observations about themselves and the world they occupy' (Stride and Fitzgerald, 2017: 100). As we have suggested already, any sport programme attempting to engage young people in activities aimed at enhancing social cohesion must be designed with the complexity of the environment in mind. There is a need, therefore, to seek methodological approaches that provide participants with a voice and ensures that any programme is culturally, socially, economically and politically relevant. Relying exclusively on wellestablished (perhaps, normalised and hegemonic) methods raises the question of whose interests are actually being served via stated interventions. Holland et al. (2008) argue that much research privileges those who are already privileged; those considered to be emotionally literate and those for whom White, male, middle class and non-disabled means of communication are the norm (see Stride and Fitzgerald, 2017). There is a need therefore, to decolonise traditional methodologies in an attempt to understand the complexities of negotiating dominance and consent, and locate the possibilities of emancipation and social change. One such approach is PAR.

PAR was chosen to promote engagement from participants and to gain their understanding of the role that sport could play in tackling ethnic divisions across the borough that threaten social cohesion. It fits the ethos and ambition of the project as it promotes both the engagement and involvement of the participants at each stage of development and creates opportunities for collaboration between participant and researcher, thus ensuring authentic local voices are not missed or dismissed in the evaluation process (Levermore, 2011). The belief is that local knowledge is pivotal to the success of 'community driven' ideas and the greater the level of community participation that exists the greater the likelihood that participants will develop an attachment and engage with the ideas and solutions to resolve the issues that affect their daily lives.

\section{Data collection and analysis}

Design and implementation of the initiative was expected to involve three broad stages. In stage one Meir, with the help of youth workers, would develop a skeleton of the initiative to later pitch to local young people. As a starting point, Meir needed to establish what challenges young people currently experience in their local communities. This baseline understanding would be established via group 
discussions facilitated by Meir. In stage two the young people would engage with the youth centre practitioners to collectively plan a sports project that they would subsequently deliver to other young people. In stage three, and with the input of the young people and youth centre practitioners, Meir would evaluate the initiative. As discussed in the next section however, a number of challenges were revealed that disrupted these plans.

Data were indeed collected in three stages with a variety of participants and stakeholders from both a local college and youth centre, but the overall outcomes were not as planned. In stage one, following the granting of ethical approval from University Centre, Blackburn and having gained their informed consent, 28 young people, recruited via the college and youth centre, participated in seven focus group discussions about various social issues within the town and how they impact upon their daily lives. Their views were also sought on the potential role that sport could play in contributing towards social cohesion. Discussions were undertaken by Meir at both a local college and youth centre. Findings from these discussions are presented in the next section. The participants were a mix of boys $(n=22)$ and girls $(n=6)$ and were aged between $15-19$ years. The participants were from either a White British $(n=13)$ or South/British Asian $(n=15)$ background. Participants were interviewed in ethnicity-specific groups with the rationale being that they would feel much more comfortable and at ease in that setting. All participants identified, to varying degrees, as having an interest in sport. This inevitably limits the generalisability of any findings, but as is identified below, an interest in sport does not necessarily resonate with a positive view of sport in general.

The second stage of data collection began with all 28 participants being invited to take an active role in the planning and delivery of a sport initiative. At first, this would involve informally engaging with the youth centre practitioners and learning about the types of initiatives currently on offer. Of the 28 , only 10 took up the offer. These 10 participants consisted of seven boys ( 3 White and 4 South/British Asian) and three girls (1 White and 2 South/British Asian) who participated in four further focus group discussions The intention of this stage of data collection was for the participants to ascertain what their shared issues were and then to work towards co-creating and eventually delivering a sport initiative in collaboration with youth centre practitioners. It is here where the research process moved from one of engaging young people on their ideas and views of their community to a participatory process whereby they became active agents in developing change. It was intended that participants would be given almost complete responsibility for the development of the initiative, thereby transferring any power that may have been held by the researcher onto participants.

However, crucially, despite the best intentions of Meir and the youth workers, the project never progressed beyond the focus group discussions as described in stage two and for a variety of reasons the intended outcomes failed to materialise. As will become clearer later in the paper, reasons for this breakdown included: lack of participant commitment, the timeframe of the project, the prescriptive nature of the original idea, a lack of conceptual clarity in relation to the proposed outcomes, and finally the participatory nature of the project.

The nature of the issues encountered meant that stage 3 of the original project had to be amended. Instead of evaluating the impact of the initiative delivered by the participants and their experiences of that, our focus changed to assessing the value of the process up to the point of breakdown in an attempt to suggest ways in which future projects could be developed and delivered more successfully. This stage involved a further three interviews: one with two youth work managers, 
another with an individual youth worker and one focus group with three young participants (two White British boys aged 17 and 19 and one South/British Asian girl aged 16). If nothing else, these failings, and subsequent changes to the research process, provide clear evidence of the complexity of seeking to deliver a project in a non-traditional and participatory way, which is not currently discussed in the literature.

All data collected during stages 1-3 were subjected to rigorous thematic analysis. The data were read and re-read to look for key themes or ideas that informed the overall narrative. We were specifically looking to establish pertinent themes existing at the intersections between participants' race/ethnicity and gender. Our analysis revealed three such themes: 1 . perception and impact of cultural divisions; 2 . development and understanding of social cohesion; and 3. the potential role of sport. It is to each of these that we now turn.

\section{Findings}

\section{Perception and impact of cultural division}

Data collected during stage one showed that the young people felt a strong sense of ethnic separation exists within this community. Separation in and of itself is not necessarily problematic. However, accompanying those perceptions of separation were feelings of fear and contempt and, to some extent, misunderstanding and blame, which are more insidious. Related to this, a view that came through strongly from young White participants in particular, was that separation was natural; something that has become almost ideological. This comment from Paul (a pseudonym) (White, aged 18) was typical of many White respondents' views:

It's just the way it is; we haven't been brought up to integrate with them [ethnic minorities] instantly have we.

Separation was not view unproblematically though. Nicole (White, aged 17) confirmed Paul's view that young White people have not necessarily been encouraged to mix and integrate with other ethnic groups, but continued by saying the same could probably be said for the way other ethnic groups approach White people:

It is really important for everyone to mix together; it is a two-way thing. It is important that you try to accept everyone, obviously there will be people that you just don't like but that is just the way it is.

Equally, Craig (White, aged 17) described the ethnic separation he witnesses as 'ridiculous' and attributed separation to damaging cultural stereotypes which, he believed, the vast majority of people did not fully understand:

I just think that the communities are just so stereotypical because of other things that are happening in the world that we don't understand. The majority of people don't understand and just jump to conclusions. People are stereotypical and this is where the majority of the problems are caused.

The White respondents tended to talk about the 'here and now' issues that exist within their community. The South/British Asian respondents were also concerned with these, but were also quick to identify the longer-term implications of ethnic separation on both the 'community' and future 
generations of young people. Faheen's (South/British Asian, aged 17) testimony was indicative of the views of other South/British Asian girls and boys in this study:

If it [segregation] carries on there won't be opportunities for our children or our children's children. A lot of people don't know, but we are living for our next generation as well, so if we are setting a bad example now it is not going to look good in the future.

Given the historical antagonisms within this region between White and South/British Asians, young people from both ethnic groups were cynical about any proposition of developing a more socially cohesive borough. That being said, there was a clear belief that segregation is unnecessary and ought to be addressed. Take this comment Nicole (White British, aged 17):

I think it is ridiculous; it is a pointless argument, just because you are a different colour of have different beliefs you should not be fighting over that. People do because they think they are better, they basically see other people with different beliefs as lower than them. You should just treat people equally.

Though respondents advocated against segregation they recognised its inescapable existence and attributed it to two issues of cultural division that exist within the borough. These were related to concerns over economic and social disadvantage. These issues are expressed succinctly and powerfully by Danny (White, aged 18):

At the end of the day, right, it does not matter where you live but in [borough] there is a division of whether you have money or if you haven't got money.

Deprivation remains highly influential on social cohesion and continues to be experienced disproportionately by minoritised ethnic groups. But we would caution against any view which assumes deprivation and social cohesion are mutually exclusive. When local authorities, voluntary organisations and others work in partnership and provide the necessary support there is no reason why communities with high levels of deprivation cannot build and develop cohesion through community programmes (see Marshall and Stolle, 2006).

Socially, there was evidence of a concern that continuing migration would dilute any coherent sense of local/regional identity (see Fletcher, 2011, 2012). For some, this perceived loss of identity had contributed to increasing levels of hostility towards different minoritised ethnic groups. For example, Hassan (South/British Asian, aged 17) remarked that:

They [White people] are seeing, like, that the Asians are taking over and they are saying that "this is Britain, this is our country". They don't want this to happen and this is where we see problems with racism happening.

Some of the young White people spoke of the visual presence (and Otherness) of South/British Asian people and in so doing, expressed a concern that White people were becoming a minority in 'their' community spaces. For example, according to Matthew (White, aged 18):

If it continues there will be a lot of separation and stuff like that. There will end up being more of them than us, there probably already is.

While the perception that "There will end up more of them than us" is a clear misconception, it is worth reflecting on where such concerns might have emerged from. Between 2000-2010 the ethnic composition of the borough changed substantially, with the South/British Asian population growing from 20\% in 2001 to $28 \%$ in 2011 (Census 2011). The rate and scale of change in this community has 
clearly created tensions between the South/British Asian communities who were attempting to establish or maintain their identities and a White British community that has grown increasingly insecure over its identity. This is not the view of the poor or the uneducated, but has seemingly become a kind of post millennial cultural diktat for explaining all manner of social and cultural issues throughout the UK. Reflecting on concerns over cultural identity, Paul (White, aged 18) referred to the challenges of adapting to increasing diversity currently facing young people:

With our generation now, you know like our mums and dads did not have lots of different cultures in the town, but there is lots of immigration now. You have just got to adapt to it really but I think we are finding it hard.

According to Bhabha (2005), multiculturalism is an almost impossibility because the homogeneous framework surrounding White (British) culture is unable to accommodate significant levels of cultural plurality. Bhabha argues that, as different cultures are constructed with different interests and evolve out of separate histories and conflicts, they will rarely share political identities, and thus, are more likely to conflict. Consequently, Arnot (2009) advocates for a more fluid conceptualisation of diversity by suggesting that cultural difference should not be conceptualised as the contrast between static majority and minority cultures.

In addition to problematising the relationships between ethnic groups, there must also be a recognition of their internal diversity. Qasim (South/British Asian, aged 17) for example, alluded to the importance of family roots as a marker of identity:

There are problems between Asians from one place and Asians from another. It is not always based upon your colour, it is more based on where you live.

Acky (South/British Asian, aged 16) reflected similarly that South Asian communities are not necessarily harmonious with one another either:

I have a lot of problems with Asians from a different area, some of them come and bully you. It is just stupid. They are trying to make a rep and show that they are hard (South Asian Male)

The key here is in acknowledging the individual contexts in which initiatives take place, combined with the tremendous diversity within ethnic groups and creating interventions that are specific to those groups. For Brah (1996), 'race' and ethnicity are not unitary; they are multidimensional, processual and require meticulous appreciation of power and differentiation. We argue that the potential to include different ethnic groups in and through sport is achievable, but strategies to engage must address individualised social needs and circumstances, rather than be superficial and tokenistic (Ratna, Lawrence and Partington, 2016).

\section{Development and understanding of social cohesion}

Stage one provided the opportunity for the young people to critically discuss complex issues that affect them on a daily basis. All respondents were able to articulate clearly the impact these issues were having on their everyday lives, but understandably, they were less clear on ways in which these issues might be addressed. This was the task undertaken during stage two of this research in which respondents were encouraged to engage with youth centre practitioners and one another on potential mechanisms and strategies that might be employed to encourage greater social cohesion through a 
sport initiative. Irrespective of their ability to articulate solutions to the issues discussed in the previous section, the young people were initially very enthusiastic about getting involved in a community project and they showed a great sense of belief that they could make a difference. Mohammed, one of two youth workers consulted during this research said:

That is the one thing that they have achieved: that through their own minds they have understood the issues that affect the town. They have a real concern about what is going on and they feel responsibility about how they can change something ... They thought they could change the world and this is the attitude that we want young people to have.

Mohammed went on to say that a primary consideration for youth worker practitioners was managing the young people's expectations about what could be achieved and what success might realistically look like.

The starting point for stage two was developing an understanding of what social cohesion meant for the young people. All participants were able to articulate some sense of what social cohesion meant, i.e., developing harmonious communities. Others however, went further than simply describing what it meant to also developing ideas about how it might be facilitated and the potential impacts of this. As Andrew, one of two youth centre managers involved in the project said:

For some within the group it has been an opportunity to channel their ideas and passion around cohesion. For others it has been a process where they are learning about cohesion and how it can impact on their lives and communities.

The young people spoke about the importance of, not only bringing different groups of people together, but doing so in a sustainable way. Rohaib (South/British Asian, aged 16) used the metaphor of a bridge to express the value of sustainable development:

If you think of people joining together to make a bridge we need the foundations there together to keep the trust together to keep the bridge together. Without that foundation the bridge is nothing. We need to build the trust together; it is the foundations that keep the bridge stable.

Developing greater levels of social cohesion within the borough is clearly a huge challenge on a number of levels. For many years, causative factors, such as ethnic segregation have been allowed to manifest largely unchallenged. Whilst steps have been made to address this issue there is still a large amount of ethnic separation. For the purposes of this paper we asked participants about the potential roles of sport in contributing towards social cohesion within this divided community. Their views are reflected in the next section.

\section{The potential role of sport}

Respondents spoke positively about their own experiences of participating in sport and of the wider role of sport in their lives. While clearly influential on a personal level, respondents questioned the overall capacity of sport to play any meaningful role in working towards greater levels of social cohesion. In particular, respondents were quick to observe the limited impact sport can make towards challenging deeply entrenched inequalities and perceptions of difference held by various ethnic groups (see Hylton and Morpeth, 2012). As Matthew (White, aged 17) said: 
I don't think that sport can probably play any role in bringing people together in the community; well not a right lot anyway. It has the potential to work but I doubt that it will. It is hard to get your views across to people and for them to listen. It is going to be hard for them to change the way they think about certain groups.

More positively however, there was evidence that, through studying and participating in sport at the college and through being involved in sport at the youth centre, some respondents identified a number of instances where their experiences had challenged (and in some cases changed) their attitudes and perceptions towards people from different ethnic groups. Reflecting on the changes witnessed since the youth centre opened, Ismail (South/British Asian, aged 17) said:

I can remember when this first opened and we came in and that night there was a fight. But things like meetings, trips, posters and interactions, have made the lads get on. There were shit loads of fights, but now we are further down the time line. People are just chilling out and getting along.

Similarly, Jamaal (South/British Asian, aged 18) spoke of the positive integrative effects of attending the youth centre and playing in mixed ethnicity football teams:

It has changed my opinion. I am not saying that I hated White people but I never used to hang around with them; so I didn't know how it was to be with White people. Right now, when I see my White friends from here I think they are actually really good guys, my opinions have changed a lot.

This evidence suggests that where there are clearly significant issues within the borough in terms of segregation, the opportunity is still there to instigate an element of meaningful change. But, the literature is divided on the transformative potential of sport. Hutchins (2007) for example, discussed how sport can exacerbate difference rather than overcome it, reinforcing group boundaries and intergroup relationships, rather than breaking them down. In a clear statement of his position he proposes that rather than ask how sport can contribute to social cohesion, we should consider how sport can help negotiate the 'inevitability' of cultural conflict and difference. The position adopted in this paper is that, where sport matters in peoples' lives, it can lead to meaningful change. However, irrespective of its level of importance, change must be co-created, reciprocal and participatory; involving young people from design, through delivery and evaluation.

The importance of involvement and ownership was reinforced by Andrew (youth work manager):

Anything led by young people has an amazing strength. Too often things are done to people rather than done with. It can enable young people to make a lasting change.

The success of any developmental approach that centralises the involvement of young people is highly contingent on their commitment. As we have already suggested, the young people involved in this research were less committed in practice than they were in theory. They spoke enthusiastically about the 'idea' of the sport initiative and made excellent and meaningful suggestions for its implementation, but when it came to the point where they were going to have to deliver their ideas, a number of young people withdrew from the process, leading to the abandonment and ultimate failure of the initiative. 


\section{Reflections on the process}

Their decision to disengage has to be put into context and so it is worth briefly reiterating the type of young people the project involved. In general they were from a low socio-economic background and had a history of disengagement within both education and society. We are conscious of avoiding essentialism and of reinforcing negative stereotypes, but they were, in the truest sense of the phrase, 'hard to engage' and, for a variety of reasons, this was unlikely to have changed through their participation in this initiative. Sohaib (youth worker) believed that the principal barriers facing most of the young people were issues in their day-to-day lives that neither the youth work practitioners nor Meir were ever fully enlightened on:

They have faced a challenge with committing to the project; they have faced basic challenges in terms of attendance. A lot of them have failed with this, to be honest, due to the other issues that are going on in their lives.

This point should not be understated. We maintain that the notion of co-production is fundamental for many community sport initiatives with young people, but if those young people are not suitably skilled to lead these, any initiative becomes like (reluctantly stated) 'the blind leading the blind'. As Heather (youth centre manager) stressed:

We have promoted the idea that the young people are the drivers of the project, we have stood off and hoped that they would take the lead and to take on the responsibility.

Further issues were caused by the nature of the intended outcome, i.e., an initiative based around sport. Criticism from those involved within the project emphasised that the initiative was overly prescriptive from the start and that they would have preferred to have greater autonomy over the focus of activities. Andrew (youth centre manager) for instance, believed that greater emphasis needed to have been placed on empowering the young people through skill development:

What we have asked them to do is a big task. There needed to be skills built in to the programme to identify the needs of the young people. They needed to be asked what they needed to make it work.

This comment opens up further criticism over the nature of the intended participatory approach favoured by the research team, and questions whether the project actually realised its participatory ambition. Andrew continued to reflect on the need for greater participation and autonomy:

It needs to be a case of them determining the process; it was perhaps too rigid and narrow. I would still use a participatory model but I would be more open and less prescriptive about what direction it could take.

For Andrew, because the initiative was not allowed to emerge organically, it was, at its core, prescriptive and therefore, flawed. Furthermore, for Heather (youth work manager), increasing engagement and understanding relies heavily on emphasising positive experiences:

Ideally you want the project to develop from a flashpoint. It can come from something that someone has said or from what young people have been speaking about with each other. Then you say 'what shall we do about this?' and you can start the project from there. 
Andrew (youth centre manager) captured this argument in his suggestion that a more fruitful approach might have been to focus on a greater number of smaller projects aimed at specific communities:

If I was to do it again I would look to work with small groups from different communities and get them to plan and develop smaller projects in each other's' communities rather than creating something large. Making it bigger does not necessarily make it better or more appropriate for the development of cohesion in the town.

The suggestion here is that participants must be enabled to develop a sense of civic engagement and critical awareness which goes beyond either sport or community development, emphasising instead, wider socio-political contexts for development.

\section{Conclusion}

The purpose of this paper was to reflect on the challenges associated with co-producing a participatory community sport initiative in working towards greater social cohesion in an ethnically segregated borough in North West England. Our starting point was to establish the nature and extent of this division, as experienced by a group of 28 White and South/British Asian young people living in this borough. We have demonstrated through both the primary and secondary data that ethnic divisions do exist within this borough. These divisions are, in large part, due to perceptions that local/regional White identities are under threat. Such perceptions have emerged due to, among other things, significant levels of migration and settlement from people of South Asian descent, the associated promotion and protection of White cultural traditions, direct and indirect racism and the creation of and subsequent racialisation of portions of the borough. It is important to acknowledge however, that diversity and division are not the same thing and that those who work in sport development and campaign for greater social justice, must establish new mechanisms for developing and embracing diversity without reinforcing divisions.

The most effective way of doing this is to develop a strategic approach that connects individual development and community development with social change. If implemented effectively, PAR is one such approach. We have discussed already how the initiative proposed at the outset of this paper failed to materialise. The original intention was to deliver a community sport initiative that was developed and designed by young people. The complexity of applying PAR methods to developing social cohesion through sport within the borough was clearly underestimated. However, it can be justifiably argued that, while the intended project was a failure, the project did bring about valuable secondary outcomes; primarily through learning opportunities experienced by the participants, researchers and youth practitioners, some of which we have extrapolated here.

Criticisms of the project, as reflected upon by the young people and youth practitioners alike, highlight the potential limitations of both sport as a stand-alone entity being used to address highly complex issues such as social cohesion, as well as the application of PAR in this context. We do not dispute these flaws, but we do maintain that there are benefits of using this approach, such as its potential to engage young people, the way it encourages participants to take ownership of an initiative and how it ensures that those who are directly affected by the issues have the opportunity to resolve them independently and through consultation. This paper reinforces the view that there is no silver bullet; the only way to fully extrapolate what is required and, therefore, to instigate meaningful 
change is to fully understand the needs, wants and desires of those for whom the change is intended. Sport, in the context of this research, does not have the capacity to transform the social system. It does however, have the capacity to instigate change on a micro level; to create a shift in the collective consciousness of community members, which should not be discounted.

The original ideas behind the project discussed here were unashamedly utopic - though by no means unrealistic - but were tempered by the reality of application. There are many positives that can be taken from this process; not least, a greater understanding has been realised about how participatory work may be applied in similar contexts in the future. This paper is unable to provide solutions to the many complex issues facing residents of this borough in North West England, but it does provide a starting point for resolving them through a desire to adopt participatory methodologies such as PAR, within a social transformative framework. There is clear value in approaching complex problems in an emancipatory way, but this must be supported more widely by other organisations, policy makers etc. The goal of creating a socially inclusive world, which is both necessary and realistic, cannot be solely a matter of the right policy or the right time. If racism and racial inequality in all aspects of life (including sport) are to cease to be of significance, then any analysis needs to be related to broader relations of power in the culture of sport and society (Carrington et al., 2016; Long et al., 2017).

The original aims of this project were clearly not met, though ironically, perhaps this paper's greatest strength is the very acknowledgement of that. When reading academic work we assume, in large part, that the data therein reflects project success. After all, this is largely why we seek to publish; to share our findings and wisdom in the hope (and expectation?) that they might be transformational and promote positive impact, whatever that might be in a specific context. Why would we want to showcase 'failed' research? Of course, research will not and does not always succeed in what it sets out to do. As researchers, we ought not to shy away from reflecting on our failures. Indeed, while we are less likely to boast about our failures and our failures certainly do not make their way into University news headlines or get included in REF impacts case studies ${ }^{4}$, in communicating failure, we are sharing valuable lessons that can be taken and translated into other (hopefully more successful) contexts.

\section{Notes}

1. In the case of this paper we use the term borough rather than town because the borough on which this paper is based contains two distinct towns; data pertaining to each town individually is not available. Therefore, it is impossible to refer to one without the other, hence their conflation.

2. We employ the term South Asian to describe individuals and communities with roots on the Indian subcontinent. The term British Asian is used to refer to those British citizens who trace their ancestry back to, or who themselves migrated from, the Indian subcontinent. It is employed as a dynamic category and its application has no firm boundaries.

3. A ward is a local authority area, typically used for electoral purposes.

4. The Research Excellence Framework (REF) was the first exercise to assess the impact of research outside of academia. Impact was defined as "an effect on, change or benefit to the economy, society, culture, public policy or services, health, the environment or quality of life, beyond academia" (HEFCE, 2016). 


\section{References}

Alexander C (2005) Imagining the Politics of the BrAsian Youth. In: Ali N, Kalra V and Sayyid S (eds) A postcolonial people: South Asians in Britain. London: Hurst, pp.258-271.

Alam F (2004) '. . . and now for the magic of Khan', Guardian, 29th August.

Arnot M (2009) Educating the gendered citizen - Sociological engagements with national and global agendas. London: Routledge.

Beutler I (2008) Sport serving development and peace: Achieving the goals of the United Nations through sport. Sport in Society 11(4): 359-369.

Bhabha H (2005) Interrogating identity: The postcolonial prerogative. In: Gay P, Evans J and Redman $P$ (eds) Identity: A reader. London: Sage, pp.183-209.

Bolton B, Fleming S and Elias B (2008) The experience of community sport development: a case study in Blaenau Gwent. Managing Leisure 13: 92-103.

Blackburn and Darwen Strategy (2013) Blackburn with Darwen Community Cohesion Strategy 20102013. Available at: https://www.blackburn.gov.uk/Lists/DownloadableDocuments/1813-DLCommunity-Cohesion-Strategy.pdf (accessed 10 February, 2017).

Brah A (1996) Cartographies of diaspora: Contesting identities. London: Routledge.

Cantle T (2009) Blackburn \& Darwen baseline community cohesion review with a focus on integration: Institute of Community Cohesion.

Carrington B, Fletcher T and McDonald I (2016) The politics of 'race' and sports policy in the United Kingdom. In B. Houlihan (ed.) Sport in Society $3^{\text {rd }}$ Edition. London: Sage, pp.222-249.

Census (2011) Blackburn and Darwen. Available at: http://www.blackburn.gov.uk/Pages/Census.aspx (accessed 10 February, 2017).

Chamberlain JM (2013) Sports-based intervention and the problem of youth offending: a diverse enough tool for a diverse society? Sport in Society 16(10): 1279-1292.

Christens BD and Dolan T (2011) Interweaving youth development, community development, and social change through youth organizing. Youth \& Society 43(2): 528-548.

Coalter $F$ (2010) The politics of sport-for-development: Limited focus programmes and broad gauge problems? International review for the sociology of sport 45(3): 295-314.

Dacombe R (2013) Sports clubs and civic inclusion: rethinking the poverty of association. Sport in Society 16(10): 1263-1278.

Darnell SC, Whitley M and Massey W (2016) Changing methods and methods of change: Reflections on qualitative research in sport for development and peace. Qualitative Research in Sport, Health and Exercise 8(5): 571-577.

Dashper K and Fletcher T (2013) Introduction: Diversity, equity and inclusion in sport and leisure. Sport in Society 16(10): 1227-1233.

Fletcher T (2011) "Aye, but it were wasted on thee": 'Yorkshireness', cricket, ethnic identities, and the 'magical recovery of community'. Sociological Research Online 16(4). Available at: http://www.socresonline.org.uk/16/4/5.html. 
Fletcher T (2012) "All Yorkshiremen are from Yorkshire, but some are more 'Yorkshire' than Others": British Asians and the myths of Yorkshire cricket. Sport in Society 15(2): 227-245.

Fletcher T (2014) “Does he look like a Paki?" An exploration of 'whiteness', positionality and reflexivity in inter-racial sports research, Qualitative Research in Sport, Exercise and Health 6(2): 244-260.

Fletcher T and Walle T (2015) Negotiating their right to play. Asian-identified cricket teams and leagues in Britain and Norway. Identities: Global Studies in Culture and Power 22(2): 230-246.

Fletcher T and Swain S (2016) Strangers of the north: South Asians, cricket and the culture of 'Yorkshireness'. Journal for Cultural Research 20(1): 86-100.

Forrest R and Kearns A (2001) Social cohesion, social capital and the neighbourhood. Urban studies 38(12): 2125-2143.

Gilroy P (2008) Melancholia or conviviality: The politics of belonging in Britain. In: Davidson S and Rutherford J (eds) Race, identity and belonging. London: Lawrence and Wishart, pp.35-46.

Haudenhuyse R, Theeboom M and Nols Z (2012) Sports-based interventions for socially vulnerable youth: Towards well-defined interventions with easy-to-follow outcomes? International Review for the Sociology of Sport 48: 471-484.

HEFCE. (2016) REF impact. Available at: http://www.hefce.ac.uk/rsrch/REFimpact/ (accessed 18 May, 2017).

Holland S, Renold E, Ross N and Hillman A (2008) Rights, 'right on' or the right thing to do? A critical exploration of young people's engagement in participative social work research. London: ESRC.

Hutchins B (2007) The problem of sport and social cohesion. In: Nieuwenhuysen JJ and Dawson E (eds) Social cohesion in Australia. Melbourne: Cambridge University Press, pp.170-181.

Hylton K and Morpeth ND (2012) London 2012: 'race' matters and the East End. International Journal of Sport Policy and Politics 4(3): 379-396.

Hylton K and Totten M (2013) Community sport development. In: Hylton K (ed.) Sport policy $3^{\text {rd }}$ edition. London: Routledge, pp.80-126.

Kalra VS (2000) From textile mills to taxi ranks: Experiences of migration, labour and social change. Aldershot: Ashgate.

Kelly E (1990) Transcontinental families in South Asians overseas. In: Clark C, Peach C and Vertovec S (eds) Migration and ethnicity. Cambridge: Cambridge University Press, pp.251-267.

Levermore R (2011) Sport-for-development and the 2010 football World Cup. Geography Compass 5(12): 886-897.

Lindsey I and O'Gorman J (2015) Not just playing the game: Possibilities of empowerment through an alternative type of engagement with sport in international development. Sociology of Sport Journal 32(1): 49-67.

Lindsey I (2013) Community collaboration in development work with young people: Perspectives from Zambian communities. Development in Practice 23(4): 481-495.

Long J, Fletcher T and Watson R (2017) Introducing sport, leisure and social justice. In: Long J, Fletcher T and Watson R (eds) Sport, leisure and social justice. London: Routledge, pp.1-14. 
Marshall MJ and Stolle D (2006) Race in the city: Neighbourhood context and the development of generalized trust. Political Behaviour 26: 125-153.

Meir D (2017) "Leadership and empowerment through sport": The intentions, hopes, ambitions and reality of creating a sport-for-development organisation in Cape Town. Journal of Sport for Development 5(8):19-29.

Perkins S (2000) Exploring future relationships between football clubs and local government. Soccer \& Society 1(1): 102-113.

Ratna A, Lawrence S and Partington J (2016) "Getting inside the wicket': strategies for the social inclusion of British Pakistani Muslim cricketers'. Journal of Policy Research in Tourism, Leisure and Events 8(1): 1-17.

Sanderson P and Thomas P (2014) Troubling identities: race, place and positionality among young people in two towns in Northern England. Journal of Youth Studies 17(9): 1168-1186.

Schinke RJ, McGannon KR, Watson J and Busanich R (2013) Moving toward trust and partnership: an example of sport-related community-based participatory action research with Aboriginal people and mainstream academics. Journal of Aggression, Conflict and Peace Research 5(4): 201210.

Schulenkorf N (2010) Bridging the divide: The role of sport events in contributing to social development between disparate communities. European Journal of Tourism Research 3(2): 127-131.

Schulenkorf N (2012) Sustainable community development through sport and events: A conceptual framework for Sport-for-Development projects. Sport Management Review 15(1):1-12.

Spaaij R (2013) Cultural diversity in community sport: An ethnographic inquiry of Somali Australians' experiences. Sport Management Review 16(1): 29-40.

Speed B (2016) How did different demographic groups vote in the EU referendum? Available at: http://www.newstatesman.com/politics/staggers/2016/06/how-did-different-demographic-groupsvote-eu-referendum (accessed 2 February, 2017).

Stephenson ML (2006) Travel and the 'freedom of movement': racialised encounters and experiences amongst ethnic minority tourists in the EU. Mobilities 1(2): 285-306.

Stride A and Fitzgerald $H$ (2017) Working towards social justice through participatory research with young people in sport and leisure. In: Long JA, Fletcher T and Watson R (eds) Sport, leisure and social justice. Abingdon: Routledge, pp.98-110.

Sugden J (2015) Assessing the sociology of sport: On the capacities and limits of using sport to promote social change. International Review for the Sociology of Sport 50(4-5): 623-627.

Whitley MA and Johnson AJ (2015) Using a community-based participatory approach to research and programming in northern Uganda: Two researchers' confessional tales. Qualitative Research in Sport, Exercise and Health 7(5): 620-641. 